\title{
The evidence for early writing: utilitarian or ceremonial?
}

\section{Nicholas Postgate, Tao Wang \& Toby Wilkinson*}

\begin{abstract}
A comparison of the evidence for the earliest scripts in different parts of the world suggests that an apparent preponderance of ceremonial; and symbolic usage should not be interpreted too literally. It seems to have more to do with archaeological preservation

- the better survival in archaeological contexts of the durable materials preferred as vehicles for ceremonial texts - than with any deep-seated differences in the function of the scripts. It may well be that the earliest Chinese, Egyptian or Mesoamerican texts were largely as utilitarian in their application as those of Mesopotamia.
\end{abstract}

While in the rest of the world's civilizations writing developed as an aspect of the religious and political power of the royal persona, here in the irrigated deserts of the Tigris and Euphrates it was basically a form of bookkeeping

COE 1992: 41

Archaic Sumerian writing was quite typical of early scripts in being primarily or exclusively used for somewhat humdrum . . . administrative purposes

SAMPSON 1985: 48

\section{Introduction}

Any enumeration of the characteristics of the early states from which modern civilization developed is bound to include writing. Like other shared external attributes, such as monumental architecture, writing is not merely a superficial manifestation of a given social order, but is embedded within it; a correct assessment of its role is essential if we are to understand the development of complex societies. The Inca state is notorious for having achieved a complex system of information exchange and retrieval without writing, but it is exceptional. It seems an a priori reasonable assumption that since writing features regularly among the attributes of early complex societies it may have played a similar role in each case. One feature which may support this assumption is the remarkable similarity of the different systems across time and space.

Similarities in some of the principal scripts revolve round the origins and development of a repertoire of 'signs', 'glyphs' or 'characters'; and round the ways in which these symbols are used to convey the language. At this point we have to make a few definitions. This is not the place to create another general definition of writing, but we do need to establish a criterion for differentiating between genuine writing, on the one hand, and symbols or systems of symbols which resemble it, on the other. Thus the complex iconography of the Olmec, although perhaps evidence for the beginning of permanent record-keeping, cannot be considered true writing. The same difficulties surround some of the symbols on early Chinese pottery, and similar marks found in many cultures including the earlier phases of Mesopotamian and Egyptian civilization. No single simple criterion is likely to suffice. Symbols may well perform a similar function to writing, such as making a statement of ownership; the difference is that writing needs always to correspond to a segment of language. Moreover, a writing system is only valid if it communicates: there has to be a reader as well as a writer, and for the system to function it must therefore be a finite

\footnotetext{
* Nicholas Postgate, Trinity College, Cambridge CB2 $1 \mathrm{TQ}$, England. Tao Wang, School of Oriental \& African Studies, University of London, Thornhaugh Street, Russell Square, London WC1H 0XG, England. Toby Wilkinson, Christ's College, Cambridge cB2 3Bu, England.
}

Reccived 9 December 1994, revised version accepted 21 April 1995, final version received 8 May 1995. 


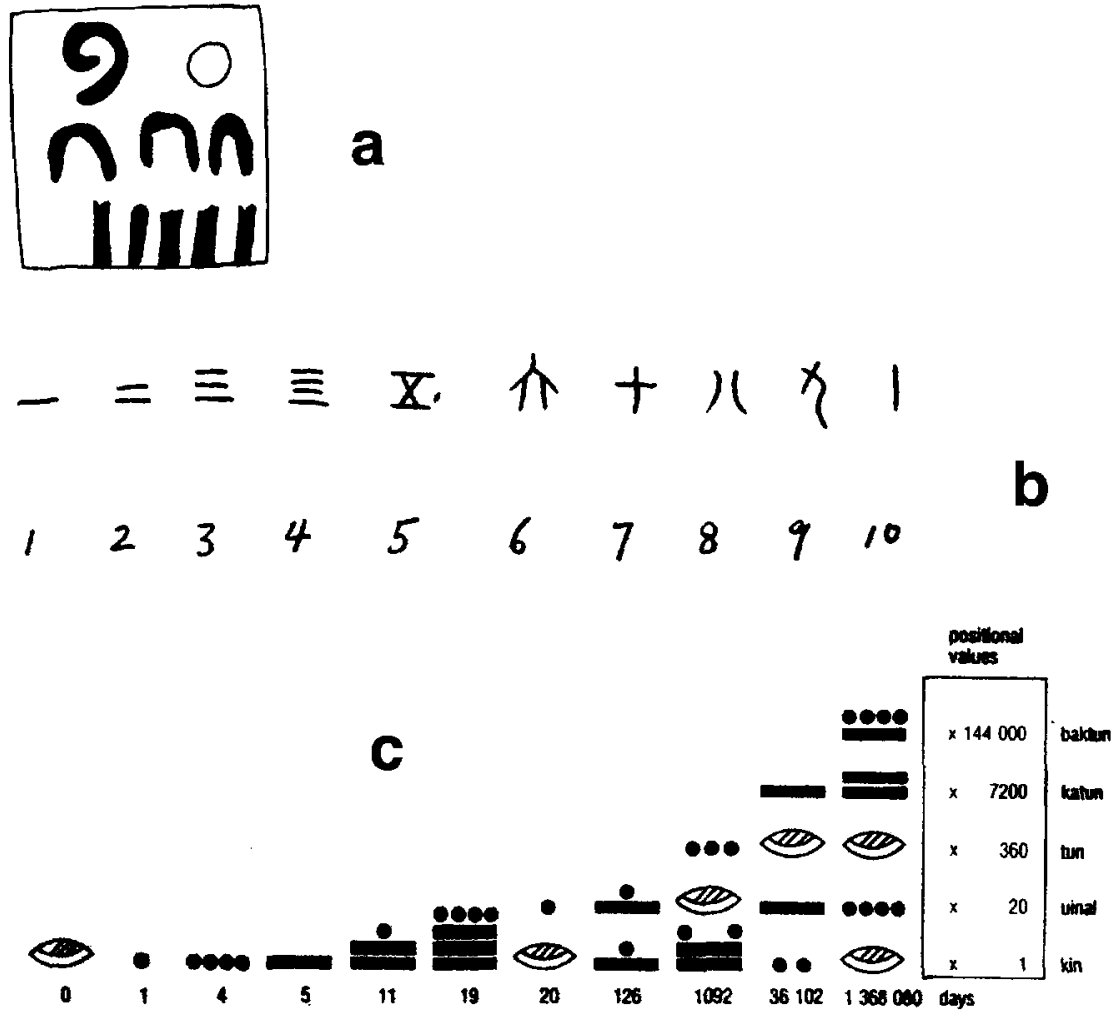

FIGURE 1. Comparison of early numerical notations

1a. Egypt: ivory label bearing the number 135 (from tomb of Neith-hotep, wife of King Narmer,
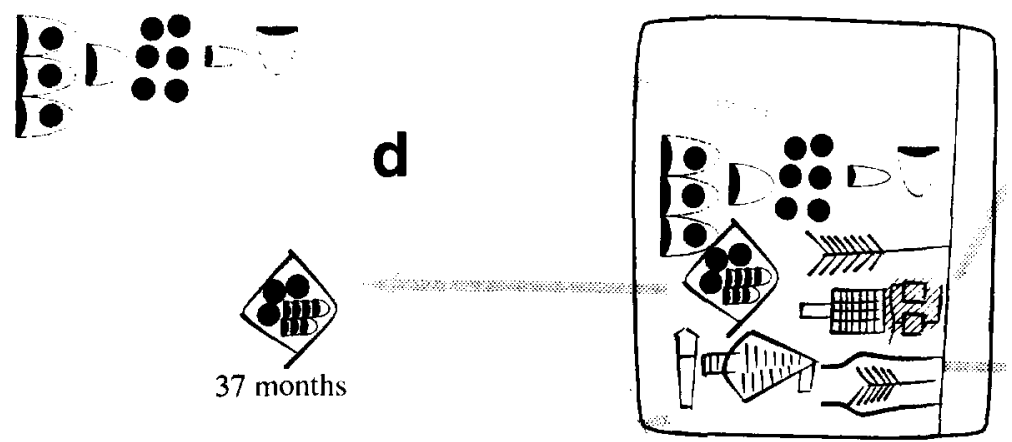
at Naqada, c. $3000 \mathrm{BC}$; after Spencer 1980: plate 51).

1b. Chinese numerals (Shang Dynasty).

1c. Mesoamerica: Maya numerical notation (after Coe et al. $1986: 118$ ).

1d. Mesopotamia: time reckoning (after Nissen et al. 1990: 67).

system, with each side sharing the same repertoire. While it is reasonable to deny that a single sign on a potsherd proves the existence of writing, it may be difficult to decide whether a combination of such symbols represents a writing system if their meaning is unknown.

The difficulty is greater because the writing systems we are discussing all originate with symbols which could well have conveyed a message independently of their role within the system. In their early stages the scripts are mostly composed of logographic symbols, ${ }^{1}$

1 Various terms have been used for these, such as pictograms or pictographs, ideograms or ideographs, logograms or logographs: usage still varies from area to area ( $c f$. for instance Coe 1992: 27 et passim; Sampson 1985), and the distinctions are not significant in the current context. 
each symbol corresponding to a word (Boltz 1986: 424). When considering the genesis of script it is interesting to compare the analysis of a much earlier academic: in the 2 nd century $\mathrm{AD}$, the earliest known Chinese lexicographer $\mathrm{Xu}$ Shen (c. AD 58-148) compiled his etymological dictionary Shuowen jiezi (Discourse on Pictographs and Explanation of Characters). In it he demonstrated examples of the Six Principles of Writing:

$\begin{array}{lll}1 & \text { zhishi } & \text { object-indicating; } \\ 2 & \text { xiangxing } & \text { form-imitating; } \\ 3 & \text { xingsheng } & \text { form plus sound; } \\ 4 & \text { huiyi } & \text { meaning-suggesting; } \\ 5 & \text { zhuangzhu } & \text { semantic-transferring; } \\ 6 & \text { jiajie } & \text { sound-borrowing }\end{array}$

In fact, as far as early Chinese writing is concerned the 'Six Principles' are over-elaborate. The zhishi, xiangxing and huiyi are basically ideographical: the forms of words correspond to the drawing of objects, or, more precisely, the meanings of the words are indicated or suggested by the characters' graphic forms. 'The zhuangzhu and jiajie principles, the crucial steps towards real 'writing', relate to the two tracks, semantic (zhuangzhu) and phonetic (jiajie) along which the writing system developed. So Boltz (1986: 426-8) describes the use of the Chinese script in this phase as 'multivalent', in that the range of words (lexemes) rendered is extended by both 'parasemantic' (using same sign for e.g. 'sun', 'light', 'shine') and 'paronomastic' (as though writing 'bear' (= 'to carry') with the picture of a bear) applications of the signs. The characters then go through similar stages in which the logograms are given (a) phonetic and (b) semantic indicators/supplements/determinatives (Boltz's phase 3).

Similar stages can be seen in the other major early scripts, such as cuneiform, Egyptian and Maya hieroglyphs. As a rule each starts as a primarily logographic system, in which each symbol represents a complete word or idea. The sources from which a repertoire of logograms was created show some similarities:

1 numerical systems (see FIGURE 1)

2 identity symbols/totems etc. (see FIGURE 2) (Matthews 1993; Coe 1992: 177-8)

3 invented pictographic signs (see FIGURE 3)

4 imitation of tokens (see FIGURE 4)
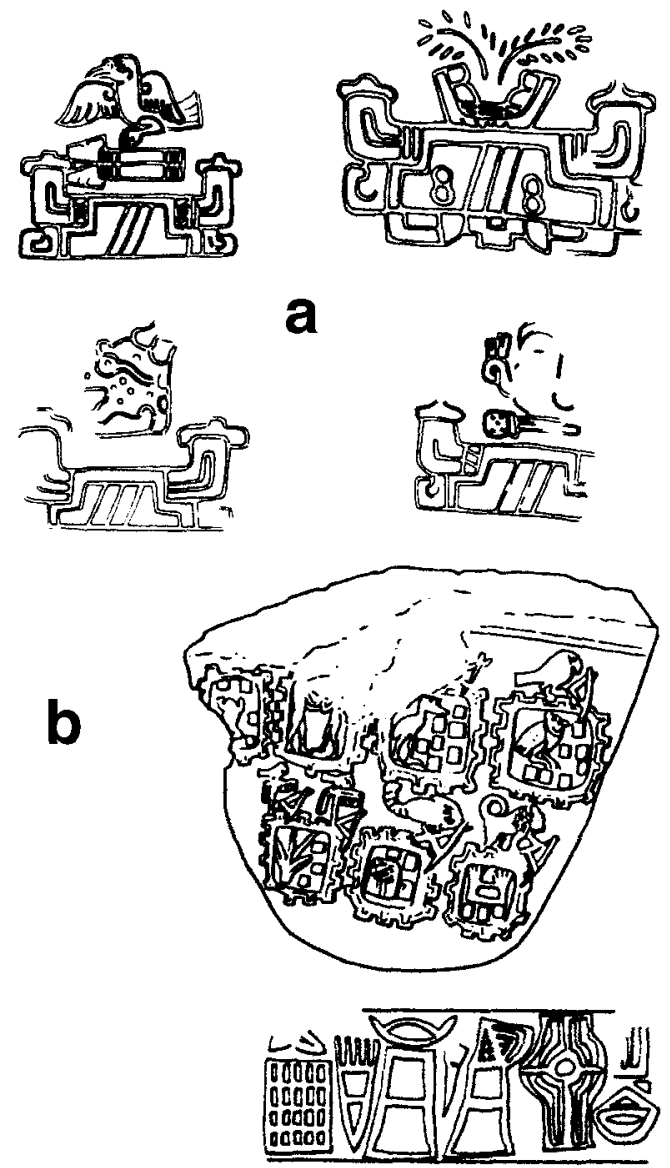

C
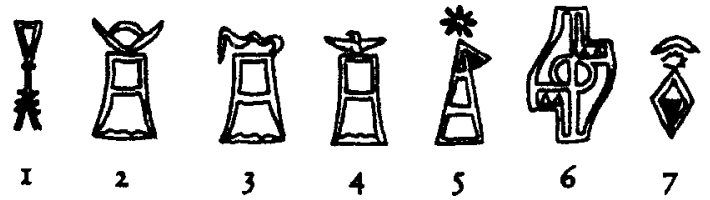

6

7

FIGURE 2. Totems and city symbols

2a. Mesoamerica: early Zapotec place signs from Monte Alban (after Marcus 1992: 176).

2b. Egypt: Pre-Dynastic city symbols (c. 3100 $B C$; after Baines 1989: 474). Compare also FIGURE 5 2c. Mesopotamia: Early Dynastic city symbols (c. 2800 BC; after Postgate 1992: 33).

Subsequent refinements and redeployments of these symbols gave the script greater facility in representing the entirety of the language. As in China, this would involve two main procedures: one is choosing a symbol to represent a sound, rather than a meaning. The other is extending the range of words or 

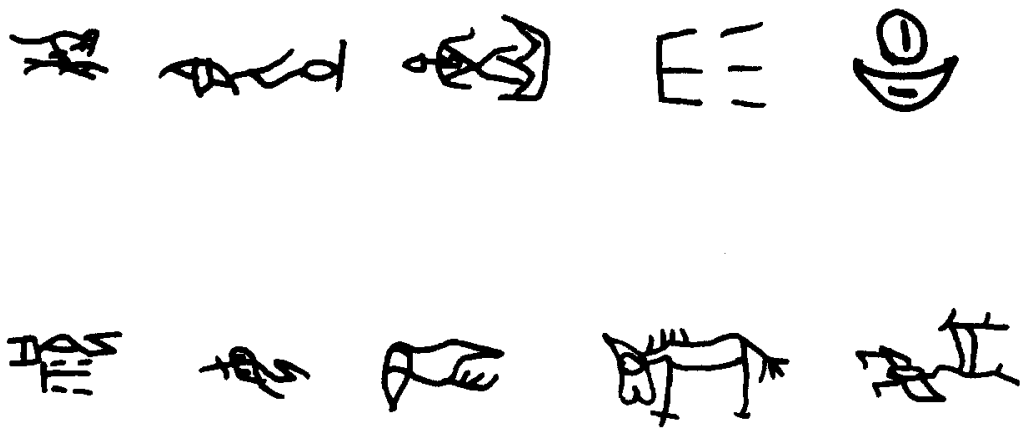

FIGURE 3. 'Invented' pictographic signs from Shang oraclebone inscription (c. $1300 \mathrm{BC}$ ).
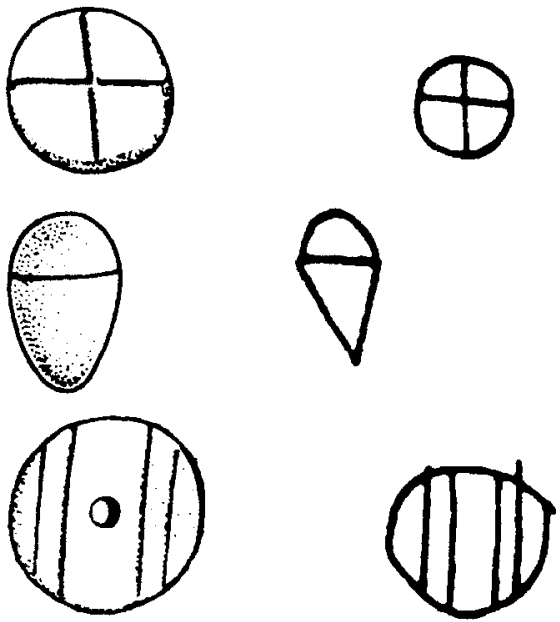

FIGURE 4. Pictographs resembling tokens (after Schmandt-Besserat 1992: 143ff.).
a. 'sheep'
b. 'oil'
c. 'textile'

concepts which each symbol may convey. The combination of the two greatly enhances the potential of a script to render a language. As they developed, the different scripts followed different routes. Some, such as cuneiform, lost some of their original repertoire of signs: visual complexity was replaced by a complexity of usage, with many signs having a variety of syllabic values but also retaining more than one logographic function. ${ }^{2}$

It is reasonable to hold that social factors had a significant impact on early writing sys-

2 For Mesoamerica Marcus asserts that 'Even from the beginnings of writing ...., the systems wore mixed or heterogeneous; they never passed through the pure stages Gelb suggests.' (Marcus 1992: 18). Perhaps this is true in terms of archaeological time (though it is based on an argumentume silentio), but we are entitled to wonder whether logically, at least, there was not an initial stage without syllabic or phonetic values. Very short periods of archaeological time can constitute a long time for those living through them. tems, as well as vice versa, and hence that study of the writing system can offer insights into society as a whole: it is not a single immutable tool in the kit for creating early states, but an adjustable spanner which responds to the task set. Given the practical advantages of a syllabic (and then alphabetic) system in the abstract, that they were not immediately adopted suggests that social and symbolic factors played a role in determining the choices, and specifically in the retention of logographic functions. One might have expected the logographic tradition to die out once the principle had been established that any word could be written by stringing together symbols representing the component syllables. Indeed, some of the pristine scripts move in this direction, such as cuneiform in the early 2nd millennium, but usually the syllabic value of a sign is additional, with its logographic value remaining in use. Even in predominantly syllabic secondary writing systems (e.g. Linear A or B) some logographic and determinative functions are retained. On the other hand, in the case of Maya writing, while logographs as a class were retained, those which were redeployed as syllabic signs seem then to have lost their logographic function (Houston pers. comm.).

In Egypt the hieroglyphic writing system was seen as having a value in its own right. In China the non-syllabic use of a sign could actually increase with time: for example, the term for an animal mask appearing on Shang bronzes, taotie, is originally an alliterative binomial which could be represented by different characters; it was only later, when the motif became closely associated with the myth of Taotie who was a 'greedy' descendant of an ancient tribe, that the 'food-element' was added to the character like a determinative in other scripts, yielding the stand- 
ard written form (Wang 1992: 109-10). To this day the three scripts used in Japan are closely controlled by the social context of their use, and through the associations of different characters more meaning attaches to a written text than the mere words conveyed: ideograms are alive and well, and the number of ideograms used is . . . growing at a healthy rate' (Bloch 1989: 30).

If therefore we see that writing developed in very similar ways independently in widely separated and unrelated times and places, it may be that in each case it was a response to similar social conditions. We do not aim to explore this major issue here, but to encourage further exploration by contending that apparent differences in the early applications of writing are more a consequence of differences in archaeological preservation than of any deep-seated differences between these first complex societies.

\section{Current opinions}

This view is not universally shared. A distinction is often drawn between 'ceremonial' and 'utilitarian' applications of writing, and it is sometimes thought that different societies tended towards one or the other extreme in their use of it. There are no self-evident reasons why this should have been so; but for some of the early states, there is a majority (but not always unanimous) opinion that the purpose of writing was more ceremonial and symbolic than utilitarian. This is well described (though not maintained) by Ray (1986: 311):

one of the distinctions frequently made between the Mesopotamian writing-system and the Egyptian ... [is that] ... Egyptian writing was essentially a royal accomplishment, used to commemorate the achievements of the palace and the status of courtiers and the king's relatives; as such it was ceremonial, designed only to record features which were already well-enough known to the ruling elite. Hieroglyphs, on this view of things, would merely be boasting made permanent.

Very similar views of New World systems are to be found among Mesoamerican scholars (Justeson 1986: 445):

Accordingly, Olmecoid writing probably originated with complex society outside the Olmec homeland, as one aspect of a visual system used ceremonially to legitimate and reinforce elite power and prestige; this would remain the principal function of Mesoamerican writing.
Our opening quotation from Coe exemplifies similar attitudes, ${ }^{3}$ and still more recently Marcus (1992: 20) has stated 'As in the case of early Mesoamerican hieroglyphic inscriptions (and in striking contrast to economic texts recorded by the early Sumerians), the functions of early Egyptian writing were to commemorate the deeds of rulers and legitimize their divine right to rule'. She continues to offer a coherent theory about the social conditions responsible for this: during the Middle Formative period chiefs 'had less institutionalised power than they wanted or needed, and therefore relied heavily on propaganda to make a case for their special powers or privileges' (1992: 32). According to Marcus, 'it was not until chiefs wanted to record their accomplishments that we see actual writing'. She thus describes Mesoamerican writing as 'both a tool and a by-product of ... competition for prestige and leadership positions' (1992: 15). Believing that 'one impetus for early writing in Egypt ... seems to have been the desire of the state to proclaim the divinity of the pharaoh and the predestined order of society' (1992: 10), she suggests that 'the origins and functions of Mesoamerican writing provide both an analogy to Egypt and a contrast to Mesopotamia'.

As for China, until very recently the principal earliest attested use of the Chinese script which survives to this day was on the Shang ceremonial bronze ritual vessels, and on oracle bones (tortoise shells and ox scapulae). Hence scholars have concentrated on its formal and ceremonial purposes: 'the fact is that available archaeological records of Shang writing - the only instruments of information transmittal that we can ever hope to find consist of group identification marks (pottery marks and bronze emblems), divination records (oracle bone inscriptions), and records of gift exchanges' (Chang 1980: 248). (Chang typically holds that 'the invention of writing in China was more associated with social identification than with economic transaction' (1980: 247) and that 'membership in one's kin group was the first thing that the first writing recorded' (1980: 248).) There is a general recognition that

3 Though compare his view in the same work (Coe 1992: 265): 'monumental inscriptions... are surely a very skewed sample of what the ancient Maya actually wrote. Gone forever are purely literary compositions...., economic records, land transactions, and, I feel sure, personal and diplomatic correspondence'. 
more utilitarian applications probably co-existed with these more formal ones, but attention remains focused on the ceremonial. Only in Mesopotamia, with its thousands of clay tablets, are the first applications of writing generally agreed to have been utilitarian. (Though Sampson has no difficulty in assuming the Mesopotamian model is valid in other instances, as our opening quotation from his book demonstrates.)

The raw facts which undermine all these statements are simply stated: for inscriptions which are meant to last, expensive and durable materials are chosen, for ephemeral and utilitarian texts cheap and perishable materials are used. Hence it is hardly surprising that it is the ceremonial texts that have survived. When Justeson comments that '... economic records are rare and late, in tribute lists' (1986: 445), we should not accept this as proof that they were written only rarely and in later times, merely as evidence that if they existed earlier they were not written on stone blocks, pottery or bronzes - no great surprise. In some or all of those civilizations where it appears that early writing was reserved for ceremonial purposes with a strong ideological bias, the early scripts must in fact have had a much wider range of uses which are now hidden from us because of the loss of perishable materials from the archaeological record.

Let us therefore examine the evidence region by region.

\section{Mesopotamia}

At present the evidence supports (though by its nature it cannot prove) the idea that writing was first put to use in Mesopotamia late in the 4th millennium BC. By far the largest body of early writing comes from Uruk, written on clay tablets in the pictographic signs which later developed into the cuneiform script. The date of the layers from which these tablets were recovered is currently taken to be around 3200$3000 \mathrm{BC}$, but the case for the originality of this script rests more on the evidence for systems of information transfer which preceded the writing system and also served as the source for some of the signs. Principally, but not exclusively, from Uruk we have evidence for a series of three-dimensional symbols, or 'tokens': some are probably numerals, others can be readily identified with animals or objects. Occasionally they are found enclosed in clay spheres over which seals have been impressed, providing a clear parallelism with the earliest tablets which bear not only incised pictographic signs but also the impressions of seals. The possibility that the similarity is coincidental becomes unlikely when we observe that some of the three-dimensional tokens are represented identically in the two-dimensional pictographs (see FIGURE 4). ${ }^{4}$

The content of the Uruk tablets is principally utilitarian, recording commodities, animals, persons and so on, presumably deriving from the bureaucracy of the temple within whose precincts the archives probably had been discarded. About $15 \%$ of the texts are what is called by Mesopotamian experts 'lexical' - that is, lists of signs (which at this date also means words) arranged in groups such as professions, trees, stones etc. These are effectively works of reference for the scribes as they learn and then ply their craft. Only later, at about $2700-2600 \mathrm{BC}$, do we begin to find texts with a non-utilitarian purpose (Postgate 1992: 66; for a recent survey of the early lexical tradition, Krispijn 1993).

Although stone was a rare commodity in Mesopotamia, and used sparingly in architecture, the scribes could have used script in public display, had they wished to (as happened later, and especially in the other early states of Egypt and Mesoamerica). They could for instance have used baked clay, or incised texts on cylinder seals, both of which would survive better archaeologically than the unbaked clay tablets, and we must assume that at this earliest stage writing was not applied to propaganda or display purposes, but served solely as an administrative device. It may be tempting to assume that it was also the preserve of the temple scribes, but this is a risky assumption. Excavated settlements of this date are scarce in south Mesopotamia, and tablets bearing purely 'numerical' texts, which have been found at widely separated sites outside Mesopotamia proper, suggest that this early version of the

4 Schmandt-Besserat's massive contributions to this subject $(1988$; 1992) have not met with universal acceptance (see e.g. Michalowski 1993), but with respect to the transition from 'tokens' to the pictographic signs from which the cuneiform system derives, the close resemblance of certain signs to virtually contemporary tokens seems unlikely to be fortuitous. 
writing system was in use outside the walls of the temples by merchants (whoever they may have been serving). Further, there is no reason to suppose that the people involved in temple administration were not equally integrated into 'secular' society at the same time, and writing equally applicable to their secular needs.

\section{Egypt}

The earliest examples of Egyptian writing to date, consisting of groups of a few signs each, come from tomb U-j at Abydos (Dreyer 1993). Clearly the tomb of a local leader (probably the ruler of the whole Thinite region and therefore possibly the direct ancestor of the kings of the First Dynasty), $\mathrm{U}-\mathrm{j}$ has been dated to $c . \mathbf{3 1 5 0}$ BC (Boehmer et al. 1993). Written inscriptions are found in the tomb in two forms:

- small bone labels incised with numerals or one to four hieroglyphic signs. The numbers have been tentatively interpreted as indicating the sizes of webs of cloth (Dreyer 1992; see FiguRE 5). The signs presumably record the provenance of different commodities since they seem to denote royal estates, administrative institutions and places such as Buto and Bubastis in the Nile Delta. The élite context of the labels is emphasized by some of the signs themselves, which include motifs such as a throne and a section of panelled, so-called 'palace-façade' architecture.

- inscriptions drawn in black ink on the sides of pottery vessels. The interpretation of these inscriptions is rather uncertain; one suggestion is that they are 'denotations of estates, indicating the provenance of the vessels and their contents' (Dreyer 1992).

Many pottery vessels from the late Predynastic period (second half of the 4th millennium BC) bear pot-marks (FIGURE 6). Comprising between one and four individual signs, often in well-attested combinations, these pot-marks have been variously interpreted. Hoffman (1980) suggested that they might be connected in some way with the origins of Egyptian writing. Helck (1990) went even further, regarding them as characters belonging to a long-vanished Lower Egyptian script; this view has not found general acceptance. Much more likely is that pot-marks belonged to a system comparable to silver
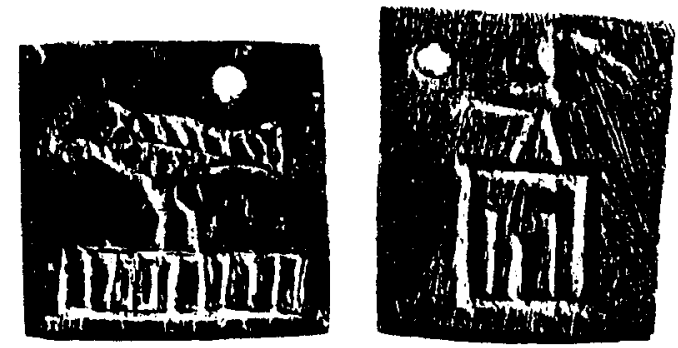

FIGURE 5. Bone labels from tomb $U_{-j}$ at $A$ abydos (Dreyer 1993: plate 7g, i).
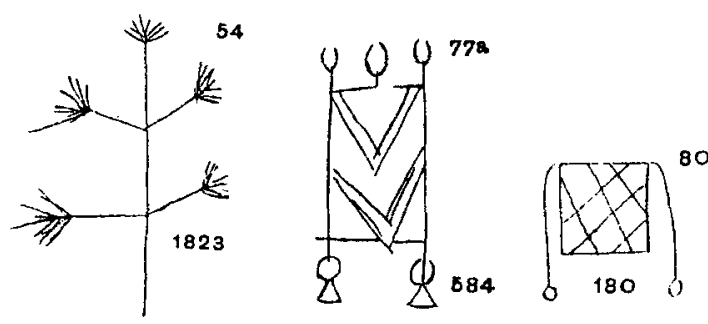

FIGURE 6. Predynastic pot marks (Petrie \& Quibell 1896: plate LII nos. 54, 77a, 80).

FIGURE 7. Ink inscription accompanying early royal name (Late Pre-Dynastic, c. 3050 BC. Spencer 1980: plate 22.301).

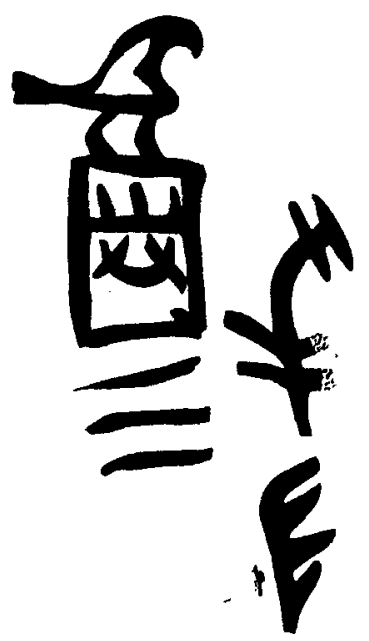

hallmarks in more recent times, whereby each sign conveyed certain information about the nature and/or provenance of the vessel contents. A single sign might suffice to convey basic information; further signs would add more details (van den Brink 1992). From at least the beginning of the Egyptian state (c.3100 BC) the system of pot-marks seems to have been standardized, suggesting a centralized administration responsible for the collection and (re)distribution of commodities. Whilst potmarks may not, therefore, be strictly described 

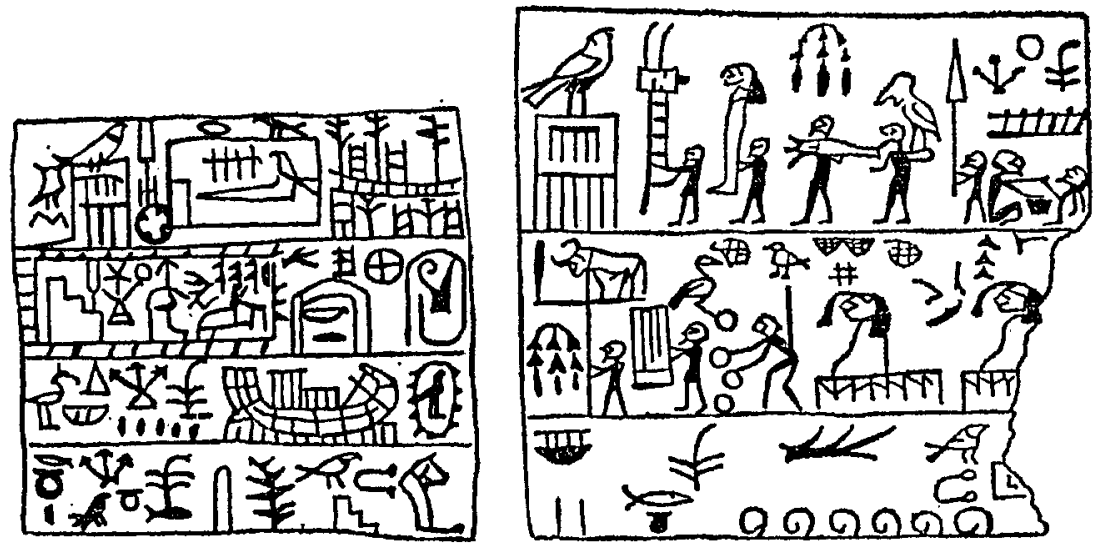

FIGURE 8. Two yearlabels, reign of King Djer, early 1st Dynasty (after Emery 1938: 35, figure 8, plates 17.A, 18.A).

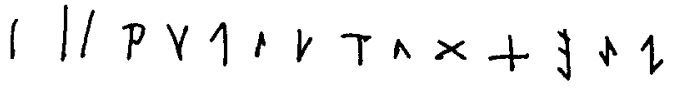

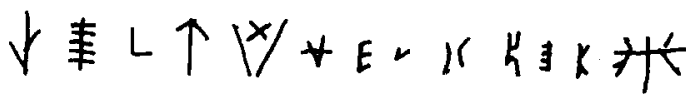

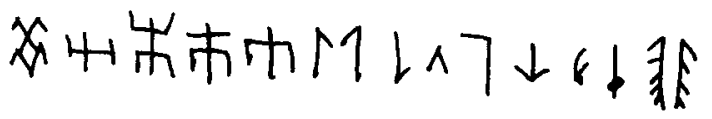

FICURE 9. Incised signs on pottery of the Yangshao Culture (c. 5000-4000 BC).

as 'proto-writing', they do seem to reflect a centralized system with a growing interest in recording information as a means of economic and administrative control.

Unambiguous examples of early writing are the ink inscriptions accompanying the earliest attested royal names (also written on the sides of pottery vessels, see FIGURE 7). Like potmarks, these seem to be concerned with recording the provenance of commodities, perhaps those collected on behalf of the king as taxes. Once again, the inscriptions fulfil an essentially economic-administrative role.

Whilst hieroglyphic writing is undeniably used during the period of state formation (late Predynastic-Early Dynastic transition, c. 3200$3000 \mathrm{BC}$ ) to commemorate royal achievements (e.g. the signs on the Narmer Palette), the earliest written evidence from Egypt suggests that writing was developed for administrative purposes.

The most remarkable feature of tomb U-j was the large number of imported Palestinian vessels (probably used to transport wine). These are clear evidence of well-developed trade re-

lations between the polities of Upper Egypt and Syria-Palestine towards the end of the 4 th millennium. It is likely that the organization and maintenance of such relations would have benefited from the ability to record transactions and to communicate over long distances.

The largest corpus of early records, dating from the first half of the First Dynasty (c. 3050c. $2950 \mathrm{BC}$ ), consists of small labels of bone, ivory or wood (FIGURE 8). Known as year-labels, they have been found exclusively in royal or élite burials, and they are clearly products of court culture: they are often made from prestige, imported materials (ebony and ivory), the inscriptions are carefully and intricately carved, and the labels were attached to highlyvalued commodities (especially oil). Although such labels often bear depictions commemorating royal events (such as foreign conquests, the jubilee festival or visits to important national shrines) their primary purpose was nonetheless an accounting one. The events served to identify a particular year of the king's reign, in turn to identify the date of the attached commodities. In these examples of early writing, therefore, the commemoration of royal events is subordinated to administrative purposes. In their intrinsic prestige and fine execution, yearlabels are clearly more than a simple administrative device. They reflect the elaboration of a technique for an élite environment. Nevertheless, they do suggest that the accounting potential of writing was both recognized and utilized by the early Egyptian rulers. The evidence of the yearlabels would thus tend to support an essentially administrative origin for Egyptian writing, as a tool developed by and for the proto-royal courts of Predynastic Upper Egypt. 

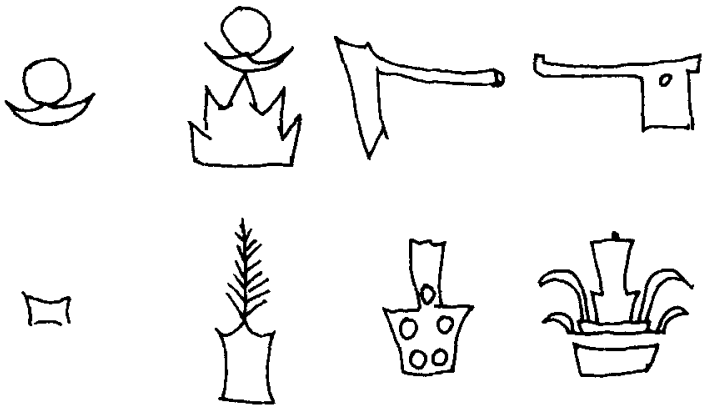

FIGURE 10. Signs found on the pottery of the Dawenkou Culture (c. 4000-2500 BC).

\section{China}

The Neolithic period in China lasted roughly from 6000 to $2000 \mathrm{BC}$. Pottery was made particularly for cooking and storing food, and on these vessels we find early signs deliberately made by man. Incised signs are found on the pottery of the Yangshao Culture which is dated to 5000-4000 BC in the Yellow River Valley (FIGURE 9). In the Banpo and Jiangzhai sites, more than 200 sherds are incised with various symbols, usually appearing in isolation. Most of them are numerical or potters' marks, and therefore cannot be treated as 'writing'.

However, many Chinese archaeologists believe that another type of signing is probably the true beginning of Chinese writing. Between 1984-87, at Jiahu, Wuyang county in Henan province, a Neolithic site of about 6500-5500 $\mathrm{BC}$, several turtle shells and a stone object were excavated, all engraved with particular signs. Because some of these signs are identical to later Chinese characters, some scholars claimed that these represented the earliest writing in the world. Certainly by comparison with the later divination texts inscribed on turtle shells one cannot a priori rule out the possibility that these were short texts with a symbolic meaning of some kind. Evidence also comes from the Dawenkou Culture (c. 4000-2500 $\mathrm{BC}$ ) on the east coast. Here on large pottery jars several signs are found, some of them comprising more than one element (see FIGURE 10). Although sign b is a compound and has been identified with a later character, it is still not certain whether it was used as a word in a writing system. More likely, as Boltz and others argue, it is a 'clan name' (Boltz 1986: 433-4).
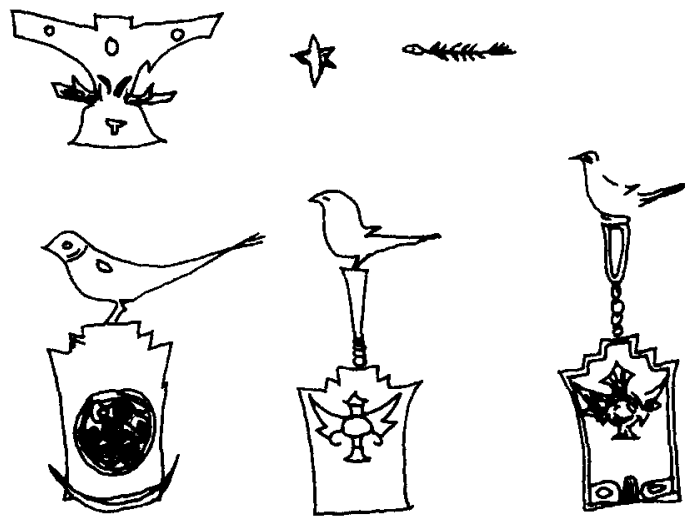

FIGURE 11. Signs incised on a jade of the Liangzhu Culture (c. 3300-2200 BC).

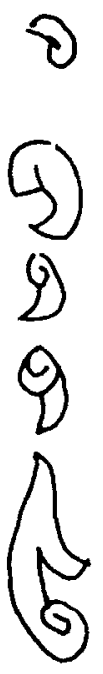

FIGURE 12. Eight symbols from a black pottery basin of the Liangzhu culture (after He 1937: 8).
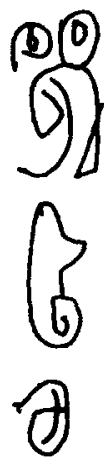


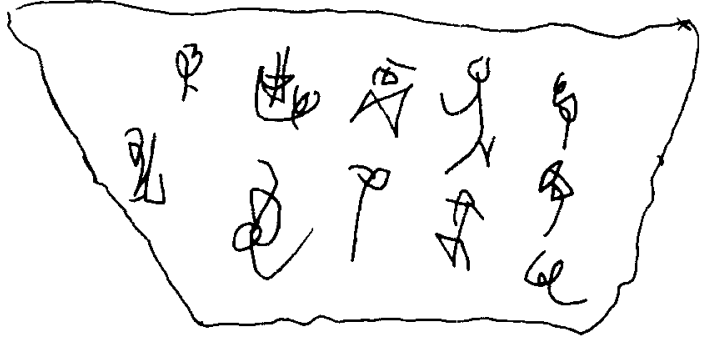

FIGURE 13. Inscription of 11 characters found incised on a pot sherd of the Longshan culture (c. $2400-1900 \mathrm{BC}$ ), discovered in Dinggong, Juxian, Shandong (L. 7.7-4.6 cm, W. 3.0-3.4 cm) (after Shandong daxue lishixi kaogu zhuanye 1993: plate 1).

The real emergence of writing in China took place between 2500-2000 BC, and has been associated with the Liangzhu Culture (c. 3300$2200 \mathrm{BC}$ ) in Southeast China, and the Longshan Culture (2500-2000 BC) in Shandong Peninsula. On Liangzhu jades several compound signs have been found (FIGURE 11), which may well be religious symbols or 'clan names', like those on the Jiahu turtle shells and on the Dawenkou jar. Moreover, signs appear not singly, but in groups, on Liangzhu pottery. A black pottery basin found in 1936 at Liangzhu town in Zhejiang province has eight signs incised on its rim (FIGURE 12). Another black pottery pot of the Liangzhu type, now in the Sackler Gallery, Harvard University, bears five signs (Kaplan 1948-9: plate XV 1c). These signs are written in a continuous sequence and are far from being pictographic. They have not been deciphered.

Writing has also been found on Longshan pottery. An important recent discovery is a sherd found in 1992 at Dinggong, Juxian county in Shandong province, which has 11 signs written in five vertical lines (FIGURE 13). Another potsherd found in 1993 in Longqiu bei, Gaoyou, Jiangsu province, also bears an inscription which may be even earlier than this (FIGURE 14). In both cases the writing is in a cursive style and looks very different from any known writing from a later period such as the Shang oracle bone inscriptions. This suggests that they may represent a different language entirely and poses enormous difficulties for decipherment.

Disregarding the signs which appear singly on Neolithic pottery and stones, it is appropri-

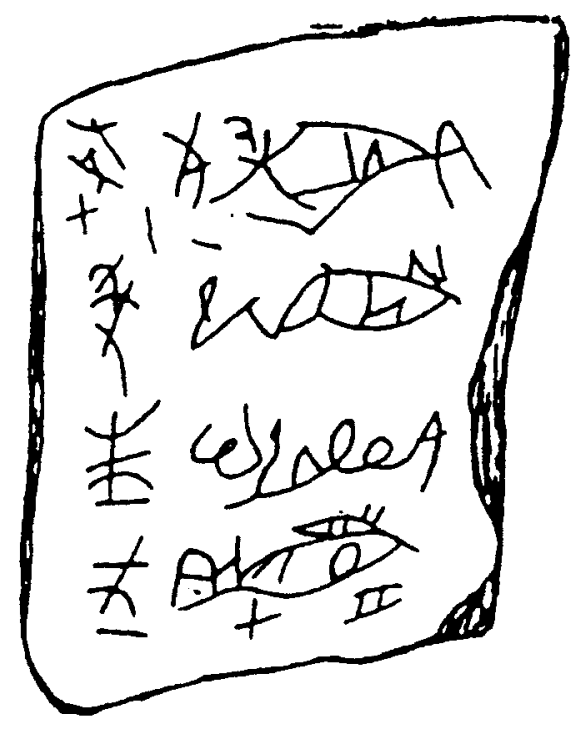

FIGURE 14. Potsherd from Longqiu (after Zhongguo wenwu bao 14 November 1993).

ate to recognize the inscriptions of more than one character found on Liangzhu and Longshan pottery as the first real 'writing' in China. At the beginning of the 2nd millennium $\mathrm{BC}$, China was at a transitional stage between the Neolithic and the Bronze Age. Evidence of abundant burials in the Liangzhu Culture reveals a high concentration of power in society. Jade carving of a very high quality has been found, as have large altars built on stamped earth platforms. In the Longshan Culture period, prototype city-states emerged in both south and north, again revealing evidence of organized state affairs. It is no surprise to find an early stage of writing among the attributes of such cultures, but as the contents of the texts on the Liangzhu and Longshan pottery have not yet been deciphered, it is impossible to know if they were made for administrative or religious purposes. Until a reliable decipherment has been made of the Neolithic scripts, we cannot be certain if they are the true ancestors of the Chinese writing system as we now know it.

A major obstacle is posed here by the time gap between the latest Neolithic writing and that of the Late Shang Dynasty 600 years later. The so-called Shang 'oracle bone inscriptions' incised on animal scapulae and turtle shells (Figures 15, 16) almost all come from one place, Xiaotun, also known as Yinxu, a farm- 


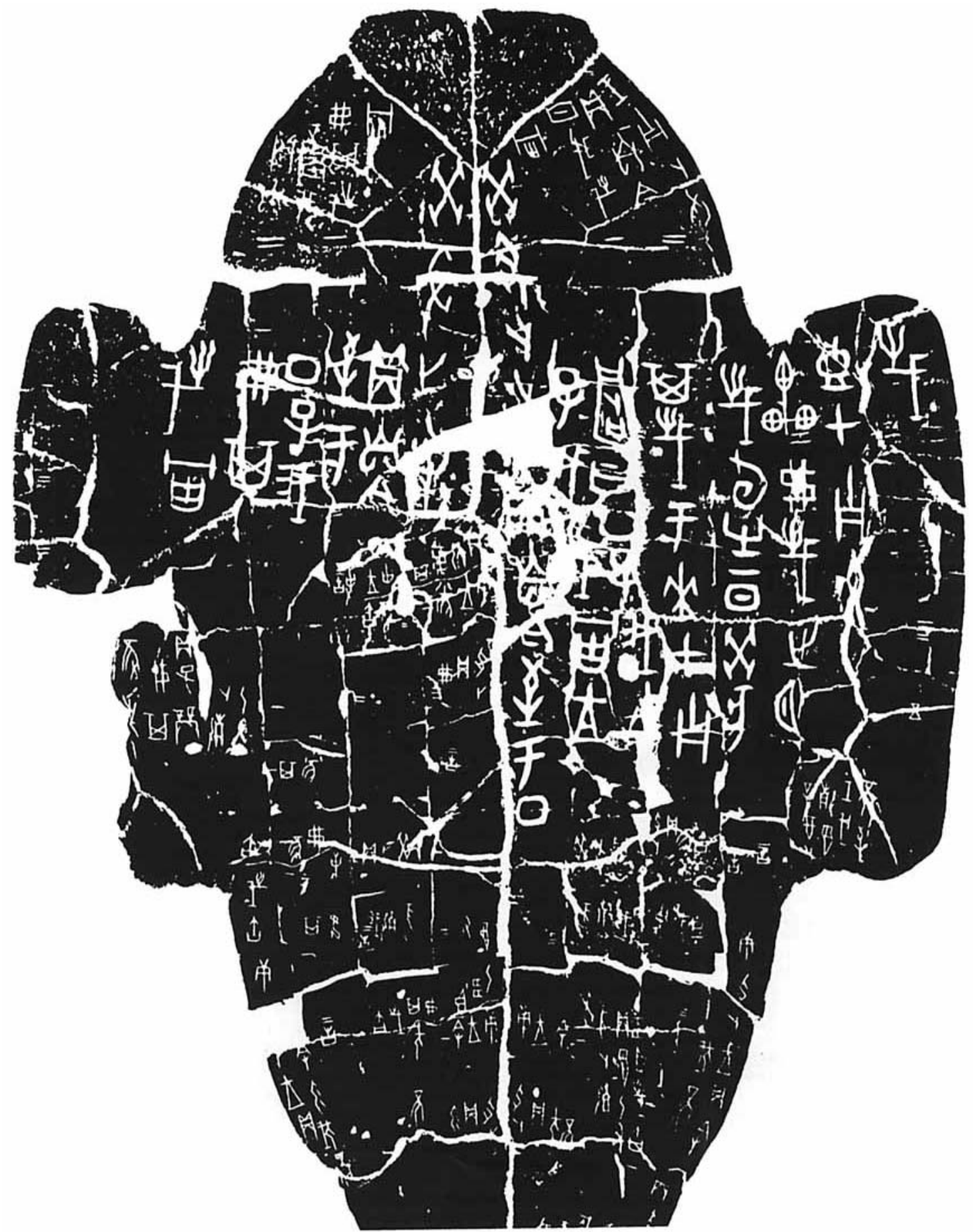

FIGURE 15. Oracle-bone inscription on turtle shell, c. 13th century BC (after Zhang 1957-72). 


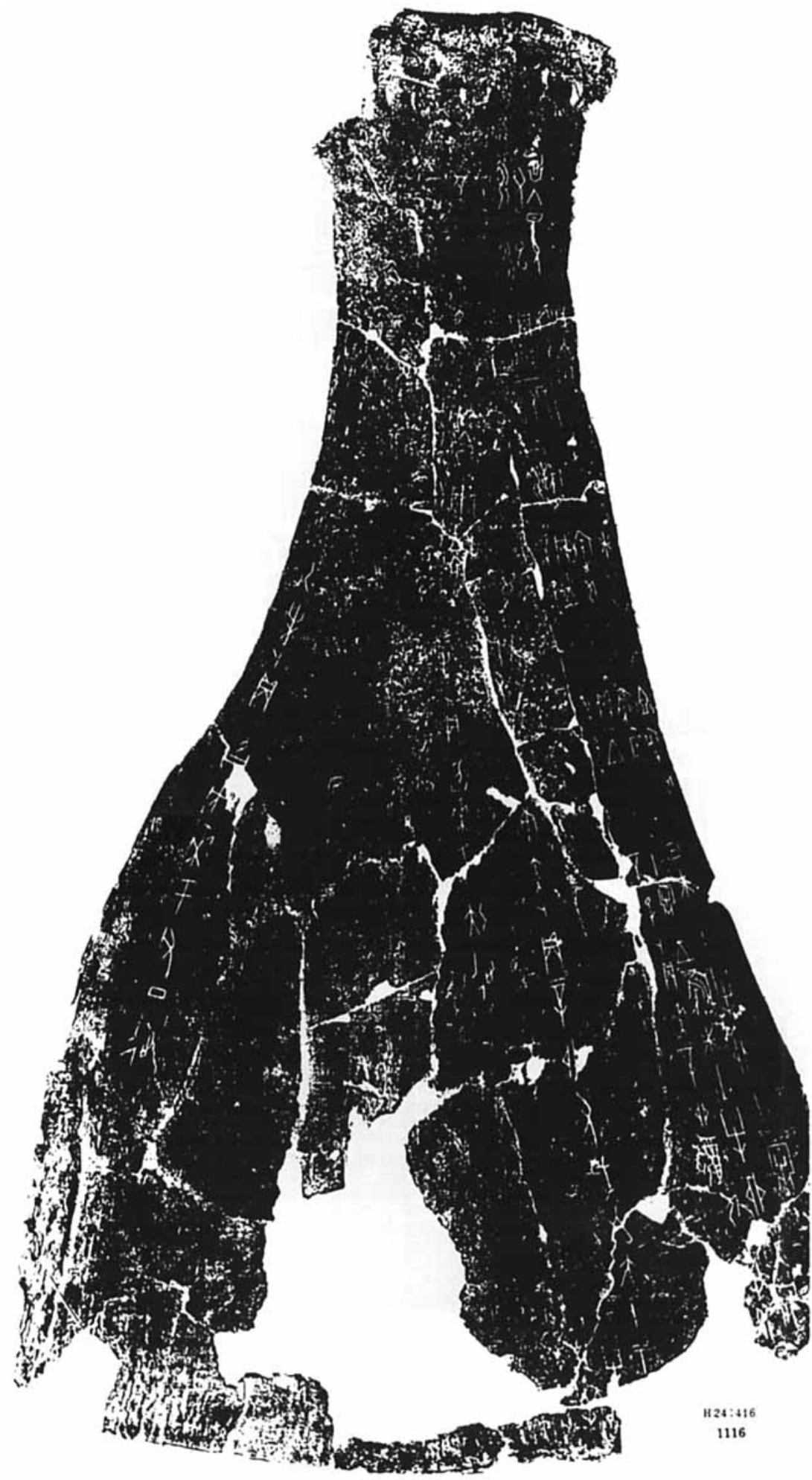

FIGURE 16. Oraclebone inscription on an ox scapula (afterzhongghuo shehui kexueyuan kaogu yanjiusuo 1980: plate 251). 
ing village in Anyang, Henan province (Keightley 1978). ${ }^{5}$ It is generally accepted now that Anyang was the royal capital of the Late Shang Dynasty, probably from the reign of King Pan Geng to King Zhou, a period of about 270 years (c. 14th-12th century BC). The recorded number of incised animal bones is well over 100,000 , although they are mostly fragments. The contents of the inscriptions cover a wide range of topics: sacrifices, military campaigns, health, travel, hunting, the weather, etc. Most of them were written as part of a divination procedure, and until recently it was assumed that the texts were all questions, and their purpose was to communicate with ancestors and spirits. However, more recent linguistic study has revealed that the majority of the texts are statements rather than questions (Qiu 1989), and the inscriptions were usually incised on the bones some days after, not during, the processes of divination, so that they constitute a kind of formal record. Although many examples have been collected through illicit digging and from disturbed earth, controlled excavation has shown that the bones were sometimes stored in groups, carefully arranged. The oracle bone inscriptions are thus neither purely for ceremonial display, nor were they ephemeral jottings, but they constituted a kind of royal archive, where records were kept for future reference.

\section{Mesoamerica}

Mesoamerica is a vast region, as varied and as large as Mesopotamia and Egypt combined. A monumental work on early writing in the entire region has recently been published by Marcus (1992); although we dissent from some of her conclusions, her comprehensive study of the subject provides a starting point for discussion.

The earliest evidence for writing in Mesoamerica comes from the societies of southern Mexico in the Middle Formative period, 700$400 \mathrm{BC}$. However, it is unlikely that these texts in stone were the first to be carved. Future excavations may well turn up earlier examples. Writing appeared in the context of warring chiefdoms, characterized by raiding and status competition. The first monuments with

5 One inscribod bone has been found at Erligang, which is a Shang site dated to an earlier period than Xiaotun (see Chen Mengiia 1956: plate 15 above right).

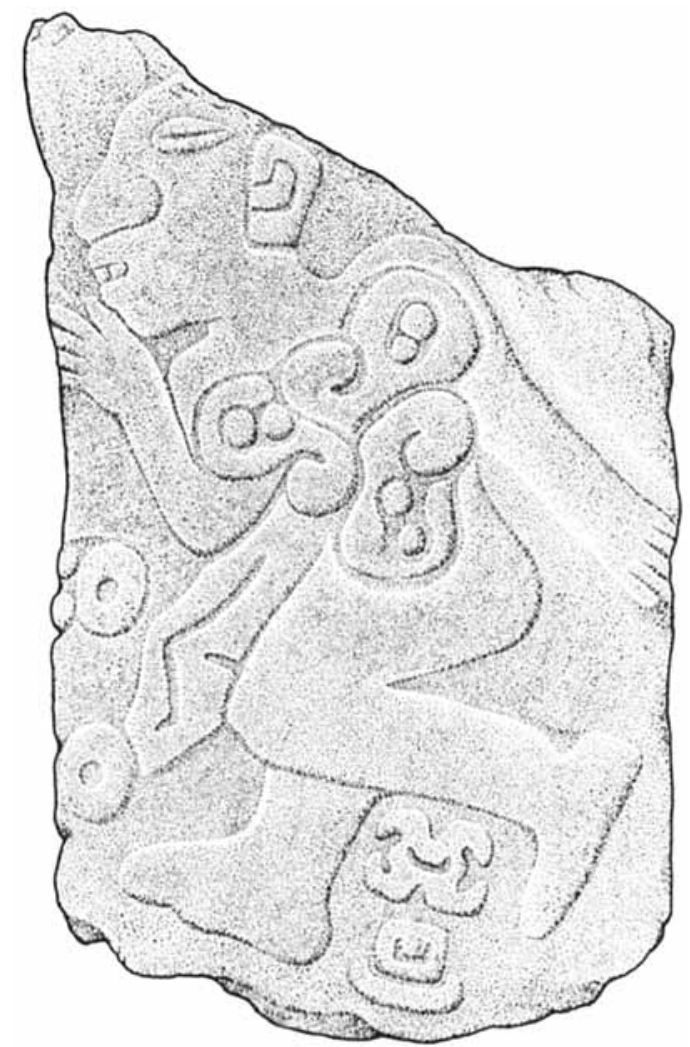

FIGURE 17. Earliest Zapotec hieroglyphic text (after Marcus 1992: 37).

writing (e.g. the earliest Zapotec hieroglyphic texts, FIGURE 17) are associated with depictions of high-status individuals, or the captives slain or sacrificed by them.

As we have noted above (p. 459), it is sometimes difficult to draw a line between writing proper and complex iconography. FIGURE 18, an example of a 'pure text', was carved at Monte Alban at approximately 500-400 BC. Both calendric and non-calendric information is given. It cannot be read but again seems to be of a military nature, probably connected with battle and the sacrifice of enemies. The text is inscribed in elaborate glyphs. One of the earliest dated Maya hieroglyphic monuments was carved at Tikal in the late $3 \mathrm{rd}$ century $\mathrm{AD}$. Like the other early texts surviving, this is a monument designed for public display and to record historical events. Later such texts are joined by complex calendrical texts. The great preponderance of all Pre-Conquest writing in Mesoamerica is carved or painted on stone or 


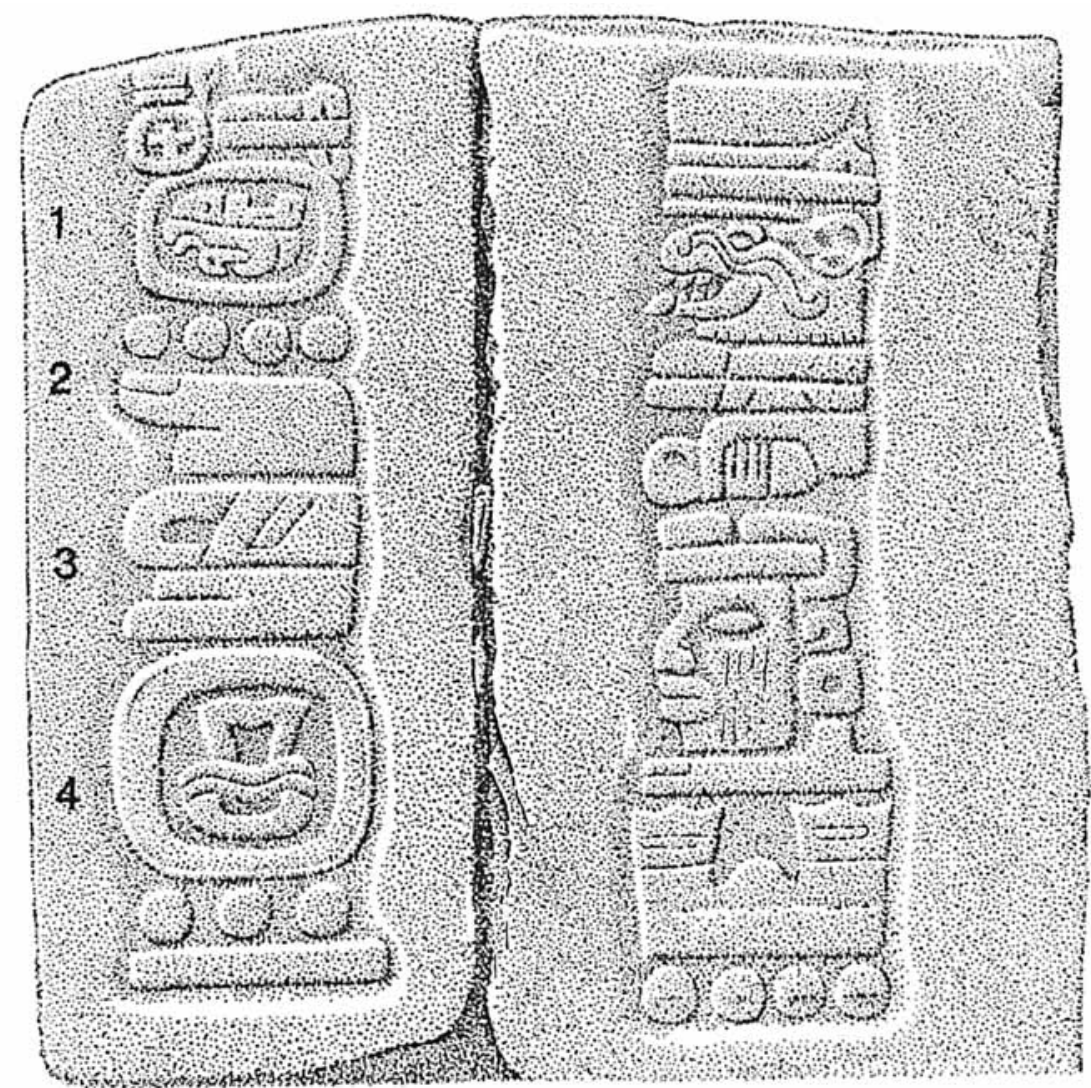

FIGURE 18. Earliest example of a 'pure text' (Monte Alban, c. 500-400 BC; after Marcus 1992: 39). on walls, but the painted pottery of the Classic period often has elaborate scenes incorporating hieroglyphic script, and there are some vessels with quite cursive inscriptions (e.g. Culbert 1993: figures 39-40, 147).

This, then, is the state of our evidence for the earliest writing in the major centres of early civilization, but it is not the whole story. In contrast to the opinion expressed in full clarity by the passage cited from Coe 1992 at the head of our article, our contention is that, as in Mesopotamia, so in Egypt, China and the Maya states writing may have been in use for everyday administrative purposes at least as early as in ceremonial contexts, if not earlier. To support this claim we underscore the importance of paying attention to the technical details of writing materials, and then see if there is positive evidence for non-ceremonial usage.

\section{Archaeological survival - durable substances} Some materials survive better than others, and for various reasons scribes chose relatively perishable substances for utilitarian texts, and more permanent vehicles for more formal ones. They were guided not only by the substance's durability, but also by its value and its convenience. Carving an inscription in stone improves its chance of survival for posterity; furthermore, the material may have been chosen for its intrinsic value (whether aimed at the inscription, or at the object, like a bowl or a statue, on which the inscription is found); and the labour of carving the text on a stone is itself an enhancement of the value of the object. As a general rule, therefore, we may expect surviving inscriptions to be those serving ceremonial purposes and found on durable materials.

Both this point, and the importance of bearing in mind the nature of the vehicle of an inscription, can be illustrated in the case of architecture. In Mesoamerica and in Egypt, where architects built stone temples and other ceremonial buildings, these often bear ceremonial inscriptions which survive to this day. In China buildings were mostly on wooden frames and have not survived, and in Mesopotamia 
neither the mud bricks nor the cuneiform script lend themselves to ceremonial inscriptions in the same measure.

There are of course exceptions, cases where non-ceremonial texts have survived. Mesopotamia is the best example: as Marcus states, 'an overwhelming number of the earliest cuneiform tablets ... appear to be records of economic transactions' (1992: 29). These tablets are, of course, made of clay; a cheap and universally available substance, when welllevigated and dried in the sun, it survives in the soil in large quantities. If the uses of early writing in Mesopotamia appear different, it could therefore be attributable to the survival potential of their daily jottings, rather than some deep ideological difference in their social fabric. Similarly, no one has suggested that writing in the Cretan and Mycenaean palaces had a ceremonial role to play, because those texts that have survived, which are on clay tablets, are of a strictly administrative nature.

Another example of a relatively durable material is lead: in central Anatolia in the early 1st millennium $\mathrm{BC}$, legal documents concerned with real estate were sometimes written in Luwian hieroglyphs on thin lead strips, as is known from rare examples from Kululu (Hawkins 1987; other lead documents are known from Assur). It is fair to assume that this was a regular practice, and the reason why more such documents have not been found is easily given: lead itself survives much better than paper or wood in archaeological contexts, but unlike clay tablets the raw material can be re-used, and doubtless these documents will normally have been recycled

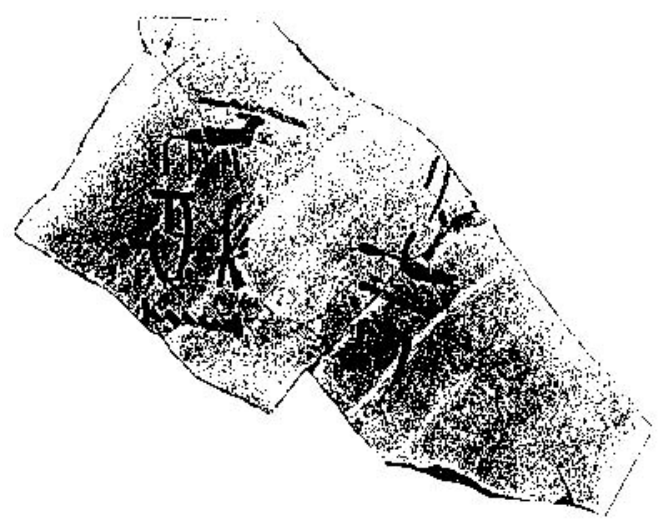

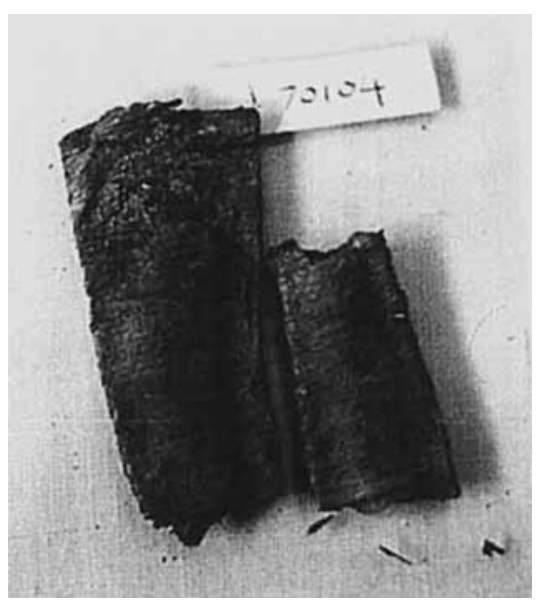

FIGURE 19. Papyrus roll from Tomb of Hemaka (Cairo Museum. Photo: A. Dodson).

once they had outlived their purpose.

Egypt is also an exception, in that the extreme dryness of some of its archaeological contexts has enabled the preservation of normally perishable substances, particularly papyrus and other organic materials (like leather). Nevertheless, surviving papyrus documents become increasingly rare as one goes back in time. The earliest attested papyrus is ironically uninscribed: a pristine roll was found in a wooden box among the grave goods of the tomb of Hemaka, a high official of King Den of the middle of the First Dynasty (FIGURE 19). Nevertheless, this find alone strongly suggests that writing was already used for documents, and one might expect a more cursive and utilitarian script to have existed. Indeed, there is con-

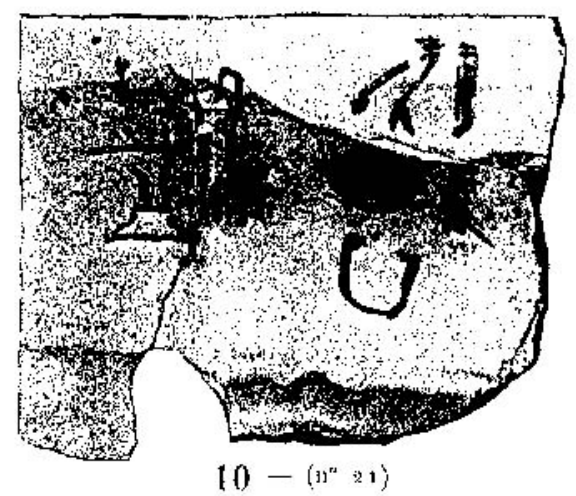

FIGURE 20. Ink inscriptions on stone bowls from beneath the Step Pyramid.

a. after Lacau \& Lauer 1965: plate 4.3.

b. after Lacau \& Lauer 1965: plate 13.10. 

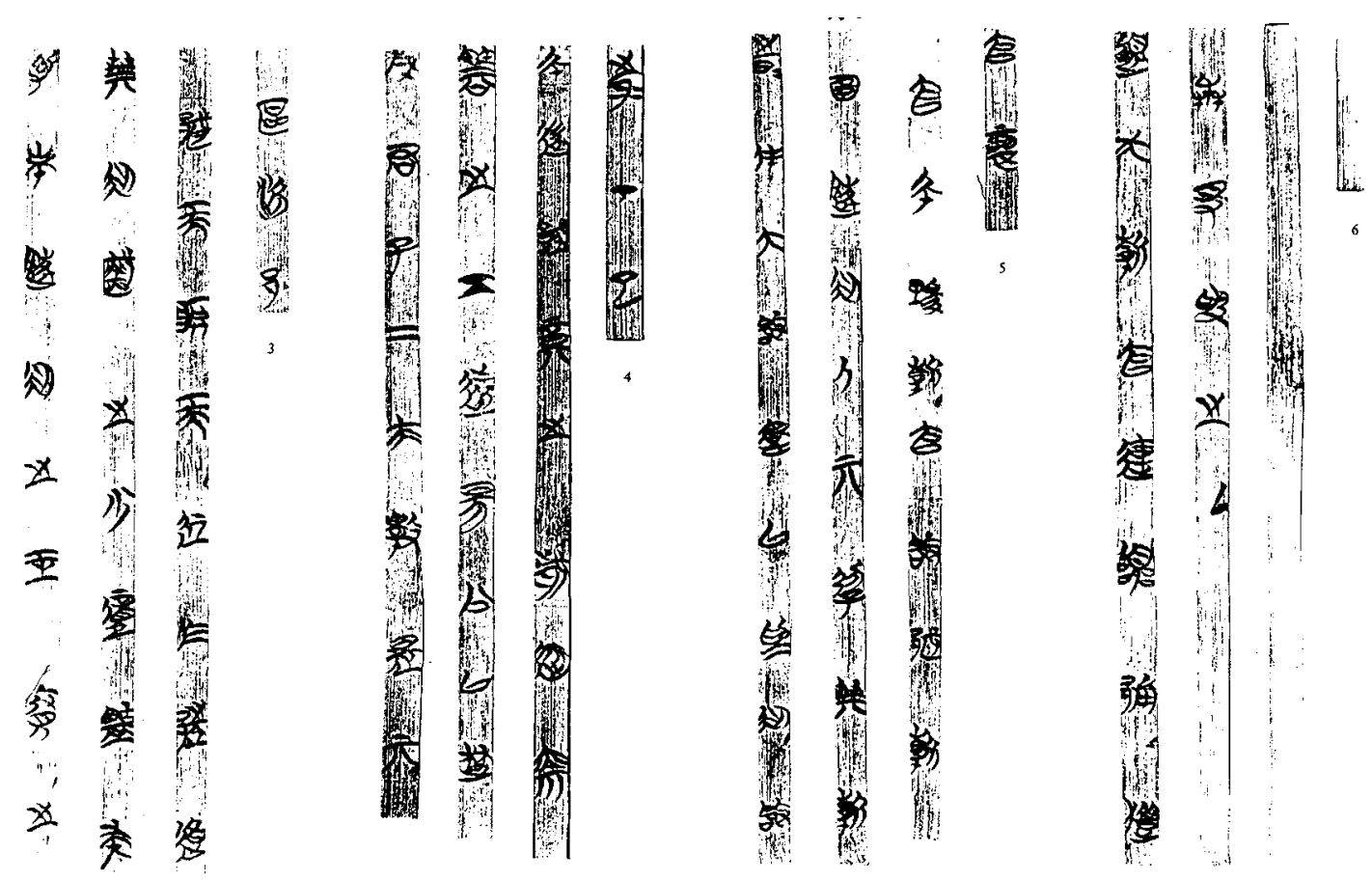

FIGURE 21. Inscribed bamboo strips from Baoshan, 4th century BC (after Hubeisheng Jing-Sha tielu kaogudui 1991: plate LXXXVIII).

temporary evidence for such a script, and it is to be found on the more durable medium of stone. Many of the stone vessels from beneath the Step Pyramid at Saqqara, some of which very probably date back to the First Dynasty, bear ink inscriptions (FigURE 20). Written in black or, occasionally, red ink, they record the details of the gift involved: the name of the donor, the occasion of the gift and, sometimes, measurements.

In China the ritual bronze vessels, tortoiseshells and scapulae are all good survivors in archaeological contexts. Shang bronze inscriptions are mostly the names of the casters and of those to whom the vessels were dedicated. Several of them do contain longer inscriptions concerning historical events, for example a particular ceremony or a military campaign. Later the Zhou bronze inscriptions all relate to ceremonial contexts; and usually, at the end of an inscription, there is a phrase saying that the vessel was made 'to pass down to the descendants to treasure it for ten thousand years'. To the Zhou rulers the texts cast on the long-lasting bronze vessels would legitimate their au- thority. The very recent discoveries from China mentioned above are also - unsurprisingly on sturdy materials (stone, pottery, tortoiseshell), and these too can only be explained on the assumption that they are the tip of a much larger iceberg of (principally) utilitarian texts written on less durable substances.

The 3rd-millennium script of the Indus sites is preserved almost exclusively on stone stamp seals (Parpola 1994: 106-13). It is ludicrous to imagine that a fully fledged script, as it certainly is, should have been developed exclusively for such a purpose. And indeed there is the occasional hint of other applications: a recent discovery at the site of Dholavira comprised Indus script characters carved out of a crystalline material, each some $37 \mathrm{~cm}$ in height and $25-27 \mathrm{~cm}$ wide, perhaps once arranged in a text on a wooden board (Bisht 1991: 81; now also Parpola 1994: 113). One must surely accept the long-standing opinion of the compiler of the new corpus of Indus seals when he writes 'Economic accounts almost certainly existed once, but they must have been written on perishable materials such as palm leaves, the tra- 
ditional writing material of India' (Parpola 1986: 403). ${ }^{6}$

Evidence for Zapotec and Maya writing systems comes mainly from carved stone monuments, while the Aztec and Mixtec systems are principally attested from painted books made of cloth, bark paper, or animal hide. These different media were used for different kinds of texts. This was also the case among the Classic Maya, where even stone monuments were differentiated according to the subject of the events being recorded, e.g. lintels were used for scenes of private ritual. However, even the Maya did not write exclusively on stone: stone monuments were the medium for formal texts, but they also included short texts in the decoration of their painted vases, and for almanacs, horoscopes and astronomical texts painted codices were used.

\section{Archaeological survival - perishable substances}

This brings us to consider what these other perishable materials might have been in the different parts of the world. In China, apart from the bone, bronze and stone inscriptions, no other writing material has survived from the Shang period. However, in later periods, texts such as ritual manuals, calendars, official regulations or lists of funerary goods are mostly written on wooden or bamboo slips. So it is reasonable to suspect that the Shang people may also have had some sort of documents written on wooden slips, and that they have not survived, due to the perishable nature of the materials used for such writing. Indeed, actual bamboo or wood strips (FIGURE 21) are attested as early as the 5th century BC and support the conclusion that these were probably the materials used for writing everyday documents in earlier times as well.

The codices on which complex texts were written in the Mesoamerican states are made of bark coated with a layer of stucco, and folded like a screen with many panels. Naturally, such documents have not survived well in the tropical lowlands of Central America. The four surviving Maya codices are from very late, just

6 The same opinion still in Parpola 1994: 54. We owe to Dr Dilip Chakrabarti the observation that such palm leaves were still in use as late as AD 1872 . See the introduction to Beverley (1873), recording that some census results were sent in from Orissa on palm-leaf documents. before the Spanish conquest, but many were incinerated by the Spanish. We can be sure they were in use much earlier, though, since several examples have been found in Classic Maya tombs, some painted but all in a lamentable condition and without legible texts (Coe 1992: 255; Pendergast 1979: 76-8; Smith 1950: 97; Kidder 1947: 70).

Some other examples of the survival of perishable writing vehicles are instructive. In the very dry climate of Egypt huge quantities of papyrus have been recovered from certain sites. But this can happen elsewhere, as with the Dead Sea Scrolls in their caves in the Judaean Desert or the copious Buddhist writings collected by Aurel Stein from Central Asia. At the other extreme, waterlogged conditions can yield surprises: Roman letters from Hadrian's Wall, or the thousands of Japanese wooden writing tablets of the 7 th century AD recovered in recent years in the Nara plain (Tsuboi \& Tanaka 1991: 67ff.). In the wreck of a Late Bronze Age ship off the southwest coast of Turkey was a small hinged wooden board instantly identifiable as a writing-board, even though no writing is preserved (Payton 1991).

Some may argue that, even when most utilitarian writing was on perishable materials, some examples would have surfaced on more durable vehicles such as the Lachish (and indeed many Classical) ostraca, or the recently recovered evidence from Anavadapura in Sri Lanka for Brahmi script on potsherds dating as far back as the 4 th century BC. This depends. Potsherds are only ever a stop-gap; in Mesopotamia, where the script required a soft substance (wet clay) and it was universally available, they were not used except very late, in the 7 th century BC, when we have some Aramaic ostraca written in ink. In Egypt they often served as a substitute for the more valuable (though still readily available) papyrus, but large administrative archives obviously would not be kept on ostraca. This is not really surprising: in Western Europe we have not used ostraca much in recent centuries, and the reason is quite simply because they are not the most convenient option: paper is cheap enough and readily available. In China it is clear that in earlier centuries sherds were indeed used, but later it is fair to suggest that the general availability of wood and bamboo removed any advantages potsherds might once have had. 


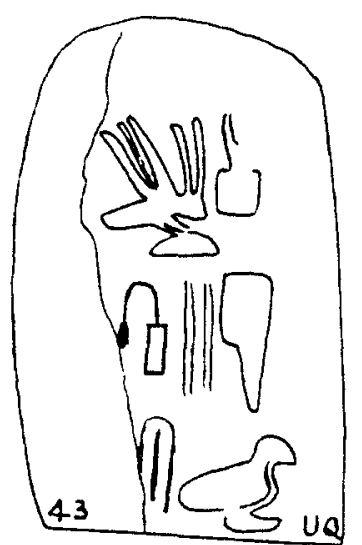

FiguRE 22. Earliest example of the hieroglyph for 'scribe' (late First Dynasty c. $2800 \mathrm{BC})$. The sign is damaged and incomplete, but its identification is not in doubt (Petrie 1900: plate XXXI.43).

\section{Indirect evidence}

In this light it may seem more reasonable for us to postulate extensive unattested uses for early writing, but the onus of proof remains on those who choose to subordinate evidence we do have to a class of evidence which has simply vanished. If a whole class of documents was regularly written on perishable substances, how can we ever come to know of them? There are various ways.

In the first place there are items associated with the technology of writing, some of which may survive better archaeologically than the documents themselves. Maya brush-holders have been found at the Late Classic site of Aguateca, Guatemala, and elsewhere (Houston pers. comm.). The brushes of the Shang Chinese and the reed styli of the Mesopotamian scribe do not survive, it is true, although brushwriting sometimes remains on the bones and various bone and metal items have been thought to be styli for clay tablets. In later Mesopotamia, when Aramaic and even Greek documents were written on leather or papyrus, we have clay labels which had been attached to scrolls which have now perished. And the wooden 13th-century Ulu Burun writing board has ivory hinges, which suggests that a careful scrutiny of some of that ubiquitous class of 'items of unknown purpose' from Late Bronze Age sites might well come across some ivory or bone 'tubes' or 'cylinders' which will turn out to be just such hinges.

Then there is the evidence of contemporary iconography, and indeed of the writing systems themselves. In Egypt the hieroglyph for 'scribe', showing the scribal kit of reed pen, ink-well and water sack - not an engraver's chisel — is

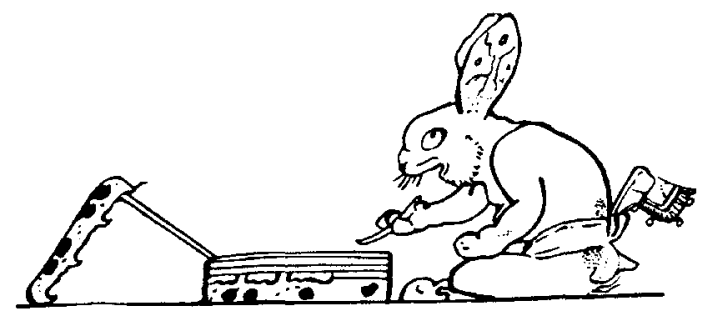

FIGURE 23. Detail showing rabbit god writing in a codex, from underworld scene on cylindrical Maya vase (c. AD 800; Princeton University Art Museum, drawing after Coe et al. 1986: 118).

attested from the late First Dynasty (FIGURE 22). Shang-period Chinese characters for 'document' (see below) show several bamboo (or wooden) strips bound together by string or fibre - not a bronze vessel or an oracle bone. For Mesoamerica, an Izapan monument from the beginning of the 1st century AD may include a depiction of a Maya screenfold. ${ }^{7}$ Codices actually being written are also shown on Maya vases, such as that shown in FIGURE 23: the rabbit god inscribing an elaborate folding codex with its jaguar-skin cover folded back (Late Classic, $c$. 8th century AD). More evidence for the long-established use of screenfolds may be preserved in the Mayan language itself, since one of the Mayan verbs for 'to write' means 'to paint' ( $t s^{\prime} i b, c f$. Coe 1992: 249). The codices were of course formal documents, the equivalent of our books: we do not know what served for the short everyday texts for which we use pieces of paper. Significant for the uses to which writing was put is the existence of a Maya 'Certified Public Accountant Deity', identifiable in the iconography already in the Early Classic Period (Berjonneau et al. 1985: plate 364).

Also the written documents themselves may offer clues. Hittite texts written on clay tablets in cuneiform often refer to documents called 'drawings' (usurtum), and it is generally felt that these were probably hieroglyphic texts on wooden writing-boards (Symington 1991). Back in Mesopotamia, texts on clay tablets tell us that wax-covered wooden writing-boards were also in use for administrative purposes from at least the 13th century BC (Postgate 1986), but the only examples that have sur-

7 The 'Tree of Life' monument, illustrated in Norman (1973: plates 9 \& 10) (reference courtesy S.D. Houston). 
vived archaeologically are a few library documents from the 1 st millennium bearing literary texts and mostly of ivory. In the Shang Chinese oracle bone inscriptions there are records of the existence of other types of writ-

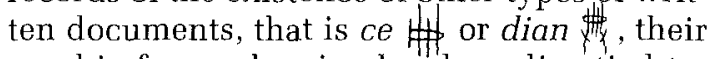
graphic forms showing bamboo slips tied together by string. In a transmitted text, the Duoshi, which survived in the Shangshu (Book of Documents) attributed to the Early Zhou Dynasty (c.900 BC), it is said that the Shang had such ce or dian - written documents on bamboo slips.

\section{Different versions of scripts - cursive vs formal}

While on the subject of the substances on which symbols were written and the relationship between those substances and the textual content of the inscriptions, we may pause to note that there are also implications for the form of the script itself. Scholars have not always taken enough account of the effect of the material used to write and the purpose of a particular text, which are often linked.

In Mesoamerica, Maya pots have cursive painted hieroglyphs, and some carved signs (e.g. Palenque's Tablet of the 96 Glyphs) clearly derive from a painted original. Coe's proposal that the elaborate decoration of many Classic vases derives from painted codices seems to have general acceptance among Mayan specialists. The effect of the writing medium on the form of the script is at its most extreme in Egypt, where writing underwent polarization into monumental hieroglyphs and cursive hieratic. While hieratic was regularly used for writing on ostraca and for dockets on pottery vessels, it should be noted that an intermediate type of writing called cursive hieroglyphs was used, exclusively for ink inscriptions on papyrus. As stated earlier, both the cursive and the monumental forms of the Egyptian script are attested from at least as early as the First Dynasty.

The oracle-bone texts differ substantially from their contemporary Shang bronzes in their content, and Boltz correctly noticed that there is a difference between the characters on bones and those cast on bronze vessels of the same period. (But there is no evidence to support Boltz's (1986: 423-4) speculation that some bronze inscriptions might be older than ora- cle-bone inscriptions.) The oracle-bone inscriptions, which were incised with a pointed knife directly onto the bone, give the impression of 'being rough and angular', whereas the bronze inscriptions, which were initially modelled onto a clay core by the bronze-workers, are more formal, replete 'with circles, ovals and curved strokes'. Boltz pointed out that such differences 'are attributable to the physical nature of the substance being written on'.

What one misses in Boltz's analysis of Chinese writing is that in the oracle-bone inscriptions there are also examples written in a much more formal style, similar to the inscriptions found on the Shang bronzes. From the calligraphy of this formal style of writing, we can see the traces of brush-work. In the early Late Shang (14th-12th centuries BC), some samples bear two different styles of writing; one is large and formal, the other small and cursive. The former is filled with a red pigment, and the latter with black. The difference was made probably with the purpose of display in mind or for reasons unknown to us (Wang 1993: 25$8)$. It is significant that a few bones are known in the late phase of this period (c. $1200 \mathrm{BC}$ ) with inscriptions which in calligraphic style and content are identical with the bronze inscriptions of this period which usually relate to ceremonies or to the casting of the vessels. In the light of this evidence, we now know that the Shang scribes were perfectly capable of producing the formal style of writing on bones if they wanted to. The main factor in deciding which script style was to be used was not purely the tools and media used for writing but also the content of the text. Likewise the amount of time devoted to a particular inscription (in turn reflecting the value attached to the text) will have had an effect on the form of the script used, with formality on ceremonial, informality on utilitarian vehicles: thus bones and tortoise-shells, though still formal, have more narrative content and generally have more cursive characters than the bronzes.

The differentiation between the cursive and formal forms of the Shang script continues to be applicable to the Early Zhou (1100-800 BC) writing when the formal style inscriptions were cast on to ceremonial bronzes. In 1976, from early Zhou architectural remains in Qishan County, traditionally known as Zhouyuan, in Shaanxi province, archaeologists found more 
than 16,000 fragments of turtle-shells and animal bones; among them there are about 280 inscribed with characters. Like the majority of Shang oracle-bone inscriptions, the Zhouyuan bone inscriptions are written in a cursive style and are too small to be read with the naked eye (Xu 1987).

Finally, there may have been deliberate archaizing of the script since archaic sign forms also have a symbolic value of their own to later generations. This is familiar today, e.g. in the use of Gothic script for horror stories, and was standard practice in cuneiform, where for instance the laws of Hammurapi carved on his stela use sign forms normal for clay inscriptions three centuries earlier. The Egyptian hieroglyphs can be seen as the example of this par excellence.

\section{Assessing relative date and importance of different applications}

In all these ways we can see that other vehicles for writing did exist, but since positive evidence for them is inevitably rare, how are we to assess their quantitative importance? How could one justify the suggestion that the utilitarian application of the script was a principal and perhaps the primary one, not a subsidiary offshoot from the well-attested ceremonial use? Proof is impossible without new evidence, but there are ways to undermine the $a$ priori assumptions based on this absence. The existence of single instances which must have belonged to a class of objects is very helpful. Thus the humble little Ulu Burun writingboard has, or should have, had a disproportionate influence on perceptions of the role of writing in the Eastern Mediterranean in the late 2nd millennium $\mathrm{BC}$, but its discovery is equally significant in a methodological way; a unique survivor of a whole class, it counters the argument 'surely if writing were so prevalent some evidence would have survived': before its discovery there was no such evidence, but the great fortune which kept it waterlogged for 3200 years or more has changed this at a stroke. It is noticeable that when large numbers of utilitarian documents have been recovered, opinions have no difficulty in adjusting, as in the case of the more than 130,000 Japanese writing tablets from 7 th-century Nara, the first one of which was only found in 1961 (Tsuboi \& Tanaka 1991: 67), or the archives of the pal- aces at Knossos and Pylos, generally taken as acceptable evidence that writing served a significant utilitarian role in those societies.

Taking a different approach, what would happen if we had no clay tablets from Mesopotamia, only the stone and metal which survive in other places? We would have a situation very similar to the Indus civilization in the $3 \mathrm{rd}-$ 2nd millennia, with legends on seals, and also inscriptions on foundation stones and texts on statues. Indeed, on such evidence we could easily suppose that ceremonial texts were the earliest usage of writing. Similarly, one could easily maintain that writing in Roman Britain was principally used for religious, civic and architectural display. It is only the chance find, like the waterlogged letters from Vindolanda, which confirms what, in the case of the Roman Empire, we do not have to be convinced of: namely that writing was widely used for everyday administrative and social purposes. So we must remember that, for other ancient cultures, whole genres of text may be missing from our evidence because of the substance on which they were written. Where, for instance, are the 16th-century BC texts of which the Proto-Sinaitic graffiti must be a fringe manifestation, and all the other Levantine writing which must have bridged the chronological gap between them and the earliest substantial West Semitic alphabetic inscriptions known to us? And are we sure that Minoan and Mycenaean scribes only wrote administrative memoranda? Could they not have composed more elaborate texts on writing-boards instead of the scrappy lumps of clay which are all we now have? In Mesoamerica there must have been a substantial usage of writing other than the ceremonial uses which have survived, since carvings on stone undoubtedly represent only a fraction of the output of Maya scribes, but the absence of evidence from earlier centuries prevents us from monitoring the formative stages of the script.

\section{Conclusion}

A popular, long-held and much-published view is that writing was developed (and, at first, used primarily) for ceremonial purposes. However, recent evidence from Egypt and elsewhere suggests instead a utilitarian, administrative origin. The medium used for writing depended largely upon the content of the message. Be- 
cause of the differential preservation of writing media, formal ceremonial texts, written on more durable substances, dominate in the archaeological record, giving a biased picture of the uses of early writing. The occasional survival of more perishable substances, together with certain other evidence, helps to correct this bias.

Taking into account all the evidence, it seems probable that early writing systems were both developed and used extensively for utilitarian purposes. This is not to deny that some components of the different scripts may have originated in ceremonial symbols, or that written texts may have served to display the agenda of a political élite. Moreover, the polarization implied by our title is of course illusory, and we have seen in Egypt, with the year-labels, and in China, with the oracle-bones, records which - while not intended for ceremonial display - were formal documents and delib-

\section{References}

BAINES, J. 1989. Communication and display: the integration of early Egyptian art and writing, Antiquity 63: $471-82$

Berjonneau, G., E. Deletaille \& 1.-L. Sonnery. 1985. Rediscovered masterpieces of Mesoamerica: MexicoGuatemala-Honduras. Boulogne: Editions Arts.

BeverLeY, E. 1873. Report on the Census of Bengal 1872. Calcutta: Bengal Secretariat Press.

BISHT, R.S. 1991. Dholavira: a new horizon of the Indus civilization, Puratattva, Bulletin of Indian Archaeological Society 20: 71-82.

BLOCH, M. 1989. Literacy and enlightenment, in M.T. Larsen \& K. Schousboe (ed.), Literacy and society: 1535. Copenhagen: Akademisk Forlag.

Boehmer, R.M., G. Dreyer \& B. KROMER. 1993. Einige frühzeitliche ${ }^{14} \mathrm{C}$-Datierungen aus Abydos und Uruk, Mitteilungen des Deutschen Archäologischen Instituts Abteilung Kairo 49: 63-8.

Boltz, W. 1986. Early Chinese writing, World Archaeology 17/iii: 420-35.

CHANG, K.C. 1980. Shang civilization. New Haven (CT) and London: Yale University Press.

Chen, Menglia. 1956. Yinxu buci zongshu. Beijing: Kexue chubanshe.

COE, M.D. 1992. Breaking the Maya code. New York (NY): Thames \& Hudson.

CoE, M., D. SNOW \& E. Benson. 1986. Atlas of Ancient America. Oxford: Equinox.

GULBER'T, T.P. 1993. The ceramics of Tikal: vessels from the burials, caches and problematical deposits. (Tikal Report 25.A). Philadolphia: University Museum. Monograph 81.

DREYER, G. 1993. Nachuntersuchungen im frühzeitlichen Königsfriedhof. 5./6. Vorbericht, Mitteilungen des Deutschen Archäologischen Instituts Abteilung Kairo 49: 23-62.

EMERY, W.B. 1938. The Tomb of Hemaka. Cairo: Government Press. erately written on durable materials. This does not undermine our contention that the stimulus to move from individual symbols or emblems to a coherent writing system is more likely to have come from the needs of administration than from a wish to disseminate propaganda. If this assessment of the role of early writing holds good, it should have a significant impact on our understanding of the emergence of complex societies, of which writing is one of the characteristic attributes.

Acknowledgements. The authors wish to express thoir considerable gratitude to several colleagues who have given generously of their time and advice: Dr Dilip Chakrabarti, Dr Aidan Dodson, Professor Norman Hammond, John D. Ray, Dr Todd Whitelaw, and in particular to Dr Gina Barnes, Professor Stephen Houston and his anonymous co-reforee who suggested substantial improvements. It is not a mere formality in this instance if we stress that they should not be hold in any way responsible for our views, for any factual errors or for any inadequacies which have persisted.

HAwKINS, J.D. 1987. The Kululu lead strips, economic documents in Hieroglyphic Luwian, Anatolian Studies 37: 135-62.

HE, TIANXIN. 1937. Hangxian Liangzhuzheng zhi shiqi yu heitao. Shanghai. Society for the Study of the History and Geography of Kiangsu and Chekiang vol. 1.

HELCK, W. 1990. Thinitischen Topfmarken. Wiesbaden: Harrassowitz. Ägyptologische Abhandlungen 50.

HOFFMAN, M.A. 1980. Egypt before the Pharaohs. London: Routledge \& Kegan Paul.

Hublisieng Jing-Sha TiElu Kaoguddu. Baoshan Chujian. Beijing: Wenwu chubanshe.

IUSTESON, J.S. 1986. The origin of writing systems: Preclassic Mesoamerica, World Archaeology 17/iii: $437-58$.

KAPLAN, S. 1948-49. Early pottery from the Liang Chu site, Chekiang Province, Archives of the Chinese Art Society of America 3: 13-42.

KEIGHTLEY, D.N. 1978. Sources of Shang history: The oracle-bone inscriptions of Bronze Age China. London: University of California Press.

KIDDER, A.V. 1947. Artifacts of Uaxactun Guatemala. Washington (DC): Carnegie Institution of Washington. Publication 576

KRISPIIN, TH.J.H. 1993. The Early Mesopotamian lexical lists and the dawn of linguistics, Joarbericht Ex Oriente LuX 32: 12-22.

Lacau, P. \& J.-Pir. Lauer. 1965. La Pyramide à Degrés V. Inscriptions à l'encre sur les vases. Cairo: Institut Français d'Archéologie Orientale.

MArcus, J. 1992. Mesoamerican writing systems. Propaganda, myth, and history in four ancient civilizations. Princeton (NI): Princeton University Press.

MatTHEws, R.). 1993. Cilies, seals and writing: urchaic seal impressions from Jemdet Nasr and Ur. Berlin: Gebr. Mann Verlag.

Michal.owski, P. 1993. Tokenism, American Anthropologist 95 : $996-9$. 
Nissen, H.J., P. Damerow \& R.K. Englund. 1990. Frühe Schrift und Techniken der Wirtschaftsverwaltung im alten Vorder Orient. Berlin: Franzbecker.

Norman, V.G. 1973. Izapa sculpture. Provo (UT'): New World Archaeological Foundation. Paper 30.

Parpola, A. 1986. The Indus script: a challenging puzzle, World Archaeology 17/iii: 399-419.

1994. Deciphering the Indus script. Cambridge: Cambridge University Press.

Payton, R. 1991. The Ulu Burun writing-board set, Anatolian Studies 41: 99-106.

Pendergast, D.M. 1979. Excavations at Altun Ha, Belize, 1964-1970 I. Toronto: Royal Ontario Museum.

PETRIE, W.M.F. 1900. The Royal Tombs of the First Dynasty I. London: Egypt Exploration Fund. Memoir 18.

Petrie, W.M.F. \& J.E. Quibell. 1896. Naqada and Ballas. London: Bernard Quaritch.

Postgate, J.N. 1986. Middle Assyrian tablets: the instruments of bureaucracy, Altorientalische Forschungen 13: $10-39$.

1992. Early Mesopotamia: society and economy at the dawn of history. London: Routledge.

QIU, XIGUi. 1989. An examination of whether the charges in Shang oracle-bone inscriptions are questions, Early China 14: 77-114.

RAY, J.D. 1986. The emergence of writing in Egypt, World Archaeology 17/iii: 307-16.

SAMPSON, G. 1985. Writing systems. A linguistic introduction. Stanford (CA): Stanford University Press.

SChmandt-Besserat, D. 1988. Tokens at Uruk, Baghdader Mitteilungen 19: 1-175.

1992. Before writing. Austin (TX): University of Texas Press.
Shandong Daxue Lishixi Kaogu Zhuanye. 1993. Shandong Zouping Dinggong yizhi di'si wu ci fajue jianbao, Kaogu 4: 295-9.

SMITH, A.L. 1950. Uaxactun, Guatemala: excavations of 1931-1937. Washington (DC): Carnegie Institution of Washington. Publication 588.

SPENCER, A.J. 1980. Catalogue of Egyptian antiquities in the British Museum V. London: British Museum Publications.

SymINGTON, D. 1991. Late Bronze Age writing boards and their uses: textual evidence from Anatolia and Syria, Anatolian Studies 41: 111-23.

TsuBOI, K. \& M. TANAKA. 1991. The historic city of Nara: an archaeological approach (trs. D.W. Hughes \& G.L. Barnes). Tokyo/Paris: Centre for East Asian Cultural Studies/UNESCO.

VAN DEN BRINK, E.C.M. 1992. Corpus and numerical evaluation of the 'Thinite' potmarks, in R. Friedman \& $B$. Adams (ed.), The followers of Horus. Studies dedicated to Michael Allen Hoffman: 265-96. Oxford: Oxbow Publications.

WANG, TAO. 1992. A textual investigation of the Taotie, in R. Whitfield (ed.), The problem of meaning in early Chinese ritual bronzes: 102-18. London: University of London, Percival David Foundation. Colloquies on Art and Archaeology in Asia 15.

1993. Colour symbolism in Late Shang China. Unpublished Ph.D dissertation, University of London.

Xu, XITAI. 1987. Zhouyuan jiaguwen zongshu. Xi'an: Sanqin chubanshe.

ZHANG, BINGQIAN. 1957-72, Xicotun di'erben: YinXu wenzi, bingbian. Taibei: Zhnogyang yanjiuyuan lishi yuyan yanjiusuo. 